J Phys Chem B. 2016 February 4; 120(4): 766-772. doi:10.1021/acs.jpcb.5b10909.

\title{
Origin of Water-Induced Fluorescence Turn-On from a Schiff Base Compound: AIE or H-Bonding Promoted ESIPT?
}

\author{
Lucas McDonald ${ }^{\dagger}$, Junfeng Wang ${ }^{\dagger}$, Nick Alexander ${ }^{\dagger}$, Hui Li ${ }^{\ddagger}$, Tianbo Liu ${ }^{\ddagger}$, and Yi Pang ${ }^{\star}{ }^{\dagger}$ \\ tDepartment of Chemistry, The University of Akron, Akron, Ohio 44325, United States \\ ‡Department of Polymer Science, The University of Akron, Akron, Ohio 44325, United States
}

\section{Abstract}

A nonfluorescent Schiff base compound (4) in an aprotic solvent (e.g., $\mathrm{CH}_{3} \mathrm{CN}$ ) is found to give blue fluorescence turn-on $\left(\lambda_{\mathrm{em}} \approx 475 \mathrm{~nm}\right)$ upon addition of $\mathrm{H}_{2} \mathrm{O}$. By using a wide range of spectroscopic methods, including ${ }^{1} \mathrm{H}$ NMR and dynamic light scattering, the fluorescence response is shown to be not originating from the molecular aggregation-induced emission (AIE). Spectroscopic studies at low temperatures further reveal a dynamic response of $\mathbf{4}$ to temperature, showing that the excited state intramolecular proton transfer (ESIPT) can be ON or OFF through interaction with protic solvent. In the binary solvent (with composition $\mathrm{CH}_{3} \mathrm{CN} / \mathrm{H}_{2} O=3: 1$ ), the Schiff base gives ESIPT emission $\left(\lambda_{\mathrm{em}} \approx 524 \mathrm{~nm}\right.$ ) only at extremely low temperature (below $-80{ }^{\circ} \mathrm{C}$ ), which is turned off when being warmed to $-60{ }^{\circ} \mathrm{C}$, attributing to the increasing photoinduced electron transfer (PET) effect. When the temperature is further raised to $-20^{\circ} \mathrm{C}$, ESIPT emission is reactivated to give blue emission $\left(\lambda_{\mathrm{em}} \approx 475 \mathrm{~nm}\right)$ that is observed at room temperature. The observed dynamic fluorescence response reveals that ESIPT could be a predominant mechanism in the fluorescence turn-on of Schiff base compounds, although both AIE and ESIPT mechanisms could operate. The assumption is further verified by examining the response of Schiff base to $\mathrm{Al}^{3+}$ cation.

\section{Graphical Abstract}

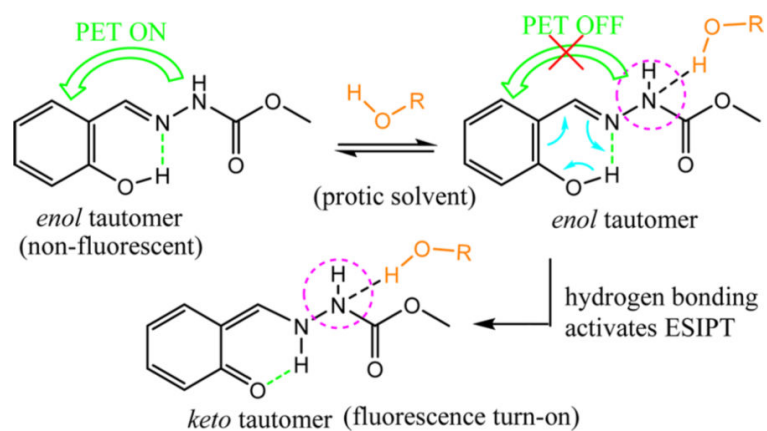

\footnotetext{
*Corresponding Author (Y.P.), yp5@uakron.edu.. The authors declare no competing financial interest. ASSOCIATED CONTENT Supporting Information The Supporting Information is available free of charge on the ACS Publications website at DOI: 10.1021/acs.jpcb.5b10909. UV-vis and normalized fluorescence of $\mathbf{4}$, crystal packing of $\mathbf{4}$, fluorescence spectra of $\mathbf{4}$ and $\mathbf{5}$, and Job plot for $\mathbf{4}$ (PDF)
} 


\section{INTRODUCTION}

For organic fluorescent dyes, one of the most useful properties is the fluorescence turn-on under a specific environmental stimulus. The fluorescence turn-on by using a different stimuli has been investigated, including molecular aggregation-induced emission (AIE), ${ }^{1}$ detection of explosives, ${ }^{2}$ metal cations,,${ }^{3-5}$ molecular anions, ${ }^{6}$ or biological tissues. ${ }^{7}$ A particular fluorescence turn-on often involves some intra- or intermolecular interaction that might be associated with molecular aggregation. For example, AIE is mainly based on the intermolecular interaction that leads to enhanced fluorescence in the solid states, which is desirable for applications such as in light-emitting diodes. Understanding the origin and mechanism for a specific fluorescence turn-on remains to be of fundamental importance in general, as it is essential for new or improved applications. ${ }^{8}$

Among the known organic fluorescent compounds, one interesting system is the hydrazinebased Schiff base 1, which integrates the molecular aggregation with intramolecular hydrogen bonding. ${ }^{9}$ Addition of water to $\mathbf{1 a}$ in ethanol turns on the fluorescence, suggesting that H-bonding plays an important role in the AIE. ${ }^{9}$ A recent study from $\mathbf{1 b}$ further shows that the AIE property could be used to selectively detect cyanide anion, presumably due to the anion's interaction with H-bonding. ${ }^{10}$ It should be noted that the compound $\mathbf{1}$ has a symmetric structure, which is a favored factor for molecular aggregation or crystallization. In addition, the phenol group in $\mathbf{1}$ can form a six member transition state with the adjacent imine bond $(\mathrm{C}=\mathrm{N})$, as shown in $\mathbf{2}$, raising the possibility for excited state intramolecular proton transfer (ESIPT). ${ }^{11}$ Since both AIE and ESIPT emissions have important practical applications, it is of fundamental importance to identify and differentiate them. Unfortunately, detailed answers to this question are not presently available.

Our recent study shows that the hydrazine-based Schiff base $\mathbf{2}$ (Scheme 1) exhibits nearly no fluorescence in aqueous, whose binding with $\mathrm{Al}^{3+}$ leads to a dramatic fluorescence turnon. ${ }^{12}$ Herein we illustrate that the structurally similar hydrazine carboxylate $\mathbf{4}$ was nonfluorescent in an aprotic solvent (such as acetonitrile), which gave enhanced blue fluorescence $\left(\lambda_{\mathrm{em}} \approx 475 \mathrm{~nm}\right.$ ) upon addition of water. Spectroscopic studies, with the aid of the model compound $\mathbf{5}$, revealed that the $2^{\prime}$-hydroxyl group was important, which is consistent with ESIPT. Various spectroscopic studies shed some lights on the nature of the fluorescence turn-on in Schiff base 4, showing that the ESIPT could be a major contributing factor. Through acquiring the fluorescence at low temperature, the study also illustrated a general approach that can be used to probe the impact of solvent reorganization on the fluorescence in a binary solvent system.

\section{RESULTS AND DISCUSSION}

2-(2-hydroxybenzylidene)hydrazinecarboxylate (4) was synthesized by reaction of aldehyde 3 with methyl hydrazinecarboxylate. Product $\mathbf{4}$ exhibited high tendency to form crystalline solid (Figure S2), whose crystal structure showed that the molecules were packed in an antiparallel fashion. Compound $\mathbf{4}$ was nonfluorescent in an aprotic solvent such as acetonitrile, THF, or $\mathrm{CH}_{2} \mathrm{Cl}_{2}$. Interestingly, addition of a protic solvent (such as water or 
ethanol) induced blue fluorescence, whose intensity was increasing with the content of water (Figure 1). As shown in Figure 1b, significant amount of water ( $>30 \%$ by volume) was required to turn on the fluorescence. The emission wavelength was also shifted to a longer wavelength, as a consequence of solvent effect (Figure 1b). The emission of $\mathbf{4}$ in water gave $\lambda_{\mathrm{em}} \approx 475 \mathrm{~nm}\left(\varphi_{\mathrm{fl}}=0.02292\right)$. Fluorescence turn-on was also observed from 2 under the same conditions, although the magnitude of the fluorescence turn-on was smaller by an order of magnitude. It appeared that the "turn-on" effect was quite sensitive to the carbonyl group, even though the group was away from the emitting molecular fragment (the aromatic phenol).

${ }^{1} \mathrm{H}$ NMR spectra of $\mathbf{4}$ were acquired in various ratio of acetonitrile/water (Figure 2). Lack of ${ }^{1} \mathrm{H}$ signal broadening suggests that the intermolecular interaction might not be changed significantly by the water content, which induced the fluorescence turn-on. In addition, UVvis absorption of $\mathbf{4}$ did not reveal any spectral red-shift upon addition of water (Figure 1a), which is typically expected when aggregates are formed. ${ }^{9}$

To seek additional evidence, dynamic light scattering (DLS) study was carried out by using the solution of 4 in $\mathrm{CH}_{3} \mathrm{CN} /$ water (volume ratio $=40: 60$ ). The concentration of $0.1 \mathrm{mM}$ was chosen to begin the study, as significant fluorescence turn-on started to occur at that concentration. Although aggregate formation would be promoted at a higher concentration, the detected scattering signal was comparable to the solvent only (Figure 3). For comparison, DLS of $\mathbf{5}$ was also examined under the same conditions, without detecting any significant scattering signals. Lack of significant DLS signals in a wide range of concentrations (100 $\mu \mathrm{M}$ to $1 \mathrm{mM}$ ) indicated that the solute did not form appreciable amount of aggregate in the solution. Clearly the $\pi-\pi$ interaction was not sufficiently strong to cause the formation of large aggregation from 4. Evidences from NMR, UV-vis absorption and DLS experiments thus suggested that the aggregate formation was less likely to be the major reason that caused the fluorescence turn-on of 4 .

Spectroscopic Studies at Low Temperature. In order to shed some light on the fluorescent turn-on process, we decided to acquire the fluorescence spectra at low temperature, which could provide insight into the intra-and intermolecular interaction. ${ }^{13}$ The study would provide additional information about the system, since the low temperature spectroscopy has the following advantages: (1) the concentration of $\mathbf{4}$ was maintained at a constant during the spectroscopic study, thus avoiding the concentration change which would affect the aggregate formation; (2) by freezing the molecule (or its conformation) in the solvent matrix, one could learn additional information that would not be available in the routine spectroscopy study at ambient temperature.

$\mathrm{CH}_{3} \mathrm{CN} / \mathrm{H}_{2} \mathrm{O}$ (3:1 ratio) was used as solvent for the study, as 4 started to give emission in the solvent composition. In order to trap the molecules in their original environment, the dilute solution of $\mathbf{4}$ in a quartz tube was quickly frozen by immersing the sample tube (with $3 \mathrm{~mm}$ inside diameter) into liquid nitrogen in a quartz Dewar. The fluorescence spectra were then acquired as the temperature was gradually raised (within about $1-2 \mathrm{~h}$ ). Interestingly, the emission of $\mathbf{4}$ gave two emission peaks at 372 and $524 \mathrm{~nm}$ when the sample was frozen at the low temperature (Figure 4a). These peaks were absent in the blank (i.e., solvent only). In 
addition, the emission of the two peaks gradually decreased when the temperature was raised (but below $-80^{\circ} \mathrm{C}$ ), suggesting that these peaks were from the true emissive species. Further raising the temperature (to above " $-20^{\circ} \mathrm{C}$ ") led to emergence of emission peak at $475 \mathrm{~nm}$, which was observed at room temperature in the presence of water (Figure 1).

The emission peak $\lambda_{\mathrm{em}}=\sim 372 \mathrm{~nm}$ was attributed to the enol tautomer of $\mathbf{4}$, since the solution 5 also gave the emission at the similar wavelength $\left(\lambda_{\mathrm{em}}=359 \mathrm{~nm}\right.$; see Figure $\left.\mathrm{S} 5\right)$. As observed in the ${ }^{1} \mathrm{H}$ NMR (Figure 2), the intramolecular hydrogen bonding was predominant when $\mathbf{4}$ was dissolved into acetonitrile. In order to understand the emission peak at $532 \mathrm{~nm}$, the spectra of $\mathbf{4}$ were then acquired in dry acetonitrile. At the low temperature (below $-80{ }^{\circ} \mathrm{C}$ ), the fluorescence of $\mathbf{4}$ gave only one predominant emission at $532 \mathrm{~nm}$ (Figure 4b), which was attributed to ESIPT emission from its keto tautomer. The result also indicated that the ESIPT was an effective process in the Schiff base phenol, since the emission from its enol tautomer (at $\sim 372 \mathrm{~nm}$ ) was almost negligible. Both emissions at 532 and $372 \mathrm{~nm}$ (observed at $-110^{\circ} \mathrm{C}$ ) were decreased with increasing temperature (Figure $4 \mathrm{a}$ ), as photoinduced electron transfer (PET) effect typically increases with temperature. ${ }^{14}$ When the temperature was raised to above $-20^{\circ} \mathrm{C}$, both enol and keto tautomers were nonemissive in dry $\mathrm{CH}_{3} \mathrm{CN}$. The ESIPT emission was only observable when the temperature was below $-60{ }^{\circ} \mathrm{C}$, since molecular rigidity reduced the molecular motions and the associated nonradiative decay.

In order to elucidate the spectra, we also examined 4 in dry $\mathrm{CH}_{3} \mathrm{CN}$. Interestingly, the emission spectra of 4 in $\mathrm{CH}_{3} \mathrm{CN}$ became much simpler at the low temperature, revealing only one major emission at $\sim 520 \mathrm{~nm}$ (Figure $4 \mathrm{~b}$ ). In addition, the emission intensity was consistently decreased as the temperature was increased, since molecular vibrations gradually became allowed. When the temperature was above the melting point of $\mathrm{CH}_{3} \mathrm{CN}$ $\left(-45^{\circ} \mathrm{C}\right)$, the emission signal was almost completely disappeared. Therefore, the seemingly complicated spectra of $\mathbf{4}$ in the binary solvent $\left(\mathrm{CH}_{3} \mathrm{CN} / \mathrm{H}_{2} \mathrm{O}\right)$ must be due to the participation of protic solvent. On the basis of these observations, we assumed that the emitting species in $\mathrm{CH}_{3} \mathrm{CN} / \mathrm{H}_{2} \mathrm{O}$ was partially solvated by water molecules (as shown in 6). As the solution of $\mathbf{4}$ was cooled in $\mathrm{CH}_{3} \mathrm{CN} / \mathrm{H}_{2} \mathrm{O}$, microphase separation could occur, since water has a higher melting point $\left(0{ }^{\circ} \mathrm{C}\right)$ than $\mathrm{CH}_{3} \mathrm{CN}\left(-45^{\circ} \mathrm{C}\right)$. In other words, some water molecules would come out to form a separate phase. Since less water molecules were associated with $\mathbf{4}$, the dye molecules might be located in the solvent cavity that was primarily consisting of $\mathrm{CH}_{3} \mathrm{CN}$, thus giving emission at $\sim 520 \mathrm{~nm}$ when the low temperature was below $-60^{\circ} \mathrm{C}$ (when molecules were frozen).

As the temperature was rising to above $-20{ }^{\circ} \mathrm{C}$ (Figure 4a), some water molecules became mobile and started to assemble to the - NH- group of $\mathbf{4}$ for $\mathrm{H}$-bonding. This could form an efficient hydrogen bonding network, which suppressed the PET and turned on the emission. The hydrogen bonding also reduced the electronic perturbation of the -NH- group, causing the emission to be blue-shifted to $\sim 475 \mathrm{~nm}$. The emission exhibited the same profile as that observed in Figure 1b, and was likely originating from ESIPT.

The spectroscopic evidence pointed to that the emission at $\sim 475 \mathrm{~nm}$ might not be associated with AIE. If the emission from the $\mathrm{CH}_{3} \mathrm{CN} / \mathrm{H}_{2} \mathrm{O}$ solution was due to aggregate, the 
aggregate structure should be preserved during the entire process of temperature change. As temperature was rising from the $-110{ }^{\circ} \mathrm{C}$ (frozen sample), the aggregate emission should be consistently decreased as the temperature was rising. ${ }^{13}$ The disappearance of emission signals $\left(\lambda_{\mathrm{em}} \approx 520 \mathrm{~nm}\right)$ at about $-60{ }^{\circ} \mathrm{C}$, followed by reappearance at about $-20{ }^{\circ} \mathrm{C}$, could not be explained by the aggregate emission. This is because most emissive molecules in the aggregates were not in direct contact with the solvents. The observed fluorescence turn-on could thus be due to competitiveness between the PET effect (quenching the fluorescence), hydrogen bonding (fluorescence turn-on) and ESIPT.

On the basis of the available evidence, an alternative mechanism was proposed in Scheme 2. In an aprotic solvent, intramolecular hydrogen-bonding was favored, and molecule tended to adopt the conformation 4 (enol tautomer). The assumption was supported by ${ }^{1} \mathrm{H}$ NMR, as protons involved in the intramolecular H-bonding were detected at $\sim 11.1 \mathrm{ppm}$ from $\mathbf{4}$ in acetonitrile (Figure 2). However, the molecule was nonemissive, due to the PET effect from an amine. Upon addition of a protic solvent (e.g., $\mathrm{H}_{2} \mathrm{O}$ ), the polar $\mathrm{N}-\mathrm{H}$ bond became solvated. The strong solvation would then weaken the PET in $\mathbf{6}$, which led to the keto tautomer 7 giving emission at $475 \mathrm{~nm}$. The intramolecular hydrogen bonding (between phenol and imine) appeared to be necessary, as the ether derivative $\mathbf{5}$ did not give the fluorescence turn-on in a protic solvent (e.g., $\mathrm{H}_{2} \mathrm{O}$ ).

\section{Metal Ion Binding}

The previous results pointed to that the emission at $\sim 475 \mathrm{~nm}$ (Figure 1b) could be attributed to the keto tautomer of $\mathbf{4}$, as a consequence of ESIPT. In an effort to further verify this assumption, we decided to examine its binding behavior to metal cations. As shown in Scheme 3, the cation binding would replace hydrogen that is responsible for the ESIPT event. Because of the weak binding of $\mathbf{4}$ in aqueous solution, the study was carried out by using methanol solvent. In methanol, the compound 4 exhibited absorption $\lambda_{\max }=321 \mathrm{~nm}$. Upon addition of $\mathrm{Al}^{3+}$ cation, the absorption peak was red-shifted to $\lambda_{\max }=362 \mathrm{~nm}$, indicating the formation of aluminum complex. The bathochromic shift was mainly attributed to the formation of an aromatic phenoxide $\left(\mathrm{Ar}-\mathrm{OH}+\mathrm{Al}^{3+} \rightarrow\left[\mathrm{Ar}-\mathrm{O}{ }^{\cdots} \mathrm{Al}^{2+}\right)\right.$ as shown in $9 .{ }^{12}$

The emission of $\mathbf{4}$ in $\mathrm{MeCN}$ was also increased significantly upon addition of methanol (Figure S3), in agreement with the proposed hydrogen bonding-induced fluorescence turnon (Scheme 3). The fluorescence of 4 (Figure 5 and Figure S3) was at $\lambda_{\mathrm{em}}=457 \mathrm{~nm}$ in methanol (very weak), which was slightly blue-shifted from that in aqueous (due to solvent effect). The emission peak was attributed to the ESIPT on the basis of large Stokes' shift $\left(\lambda_{\mathrm{em}}-\lambda_{\max }=136 \mathrm{~nm}\right)$ and lack of spectral overlap between the absorption and emission spectra. Upon addition of $\mathrm{Al}^{3+}$ cation, the emission at $457 \mathrm{~nm}$ disappeared, along with a much stronger signals at $432 \mathrm{~nm}$ as the aluminum complex was formed. The emission at 432 $\mathrm{nm}$ continued to increase until about 1.4 equiv of $\mathrm{Al}^{3+}$ was added. Observation of the aluminum-phenoxide emission (at $432 \mathrm{~nm}$ ), at the cost of the emission (at $457 \mathrm{~nm}$ ), further supported the assumption that the protic solvent-induced emission from 4 was originating from ESIPT (not aggregation). The observation was consistent with the spectral assignment that the emission at $457 \mathrm{~nm}$ was due to ESIPT. When an ESIPT probe binds the metal ion, a 
unique signature is that the absorption $\lambda_{\max }$ will exhibit a large bathochromatic shift (as a consequence of $\mathrm{Ph}-\mathrm{OH} \rightarrow \mathrm{Ph}-\mathrm{O}^{-}$), while the emission $\lambda_{\mathrm{em}}$ is shifted to a shorter wavelength (due to removal of ESIPT). ${ }^{15}$ For an aggregation species, both absorption $\lambda_{\max }$ and fluorescence $\lambda_{\mathrm{em}}$ are expected to move toward a longer wavelength upon formation of aluminum complexes. Thus, the solvent-induced emission from 4 at $457 \mathrm{~nm}$ could not be an aggregation band. If the aggregate was involved, one would have multiple emissive species due the equilibrium "aggregate" $\leftrightarrow$ "single dye", and the resulting complexes would be $\left[\right.$ "aggregate" $\left.-\mathrm{Al}^{3+}\right]$ and ["single dye molecule"- $\mathrm{Al}^{3+}$. Since the aggregate and single molecular species have different absorption $\lambda_{\max }$ and fluorescence, their spectral responses are not expected to give a clear isosbestic point. ${ }^{16}$

The mass spectrum of sample $4+\mathrm{Al}\left(\mathrm{NO}_{3}\right)_{3}$ in methanol detected the peak at $\mathrm{m} / \mathrm{z} 282$ (Figure 6), which matched the isotope pattern for $\mathrm{C}_{9} \mathrm{H}_{9} \mathrm{AlN}_{3} \mathrm{O}_{6}$ (corresponding to [4-H + $\left.\left.\mathrm{Al}^{3+}+\mathrm{NO}_{3}{ }^{-}\right]^{+}\right)$. No mass peak corresponding to $\left.\left[\left(4-\mathrm{H}^{+}\right)_{2}\right)+\mathrm{Al}^{3+}\right]$ was observed. The result indicated the formation of a complex with 1:1 ligand-to-metal ratio, and supported the possible formation of the bicyclic-structure 9. Deviation from 1:1 metal-to-ligand binding ratio, observed from the absorption and fluorescence titration, could be attributed to the weak binding of the amino group (-NH-) to $\mathrm{Al}^{3+}$ cation. Fluorescence response of 4 to various metal cations also exhibited excellent selectivity (Figure 7), showing that the formation of the bicyclic-structure (shown in 9) would be a useful template for selective binding $\mathrm{Al}^{3+}$ cation.

\section{CONCLUSION}

The nonfluorescent Schiff base 4 in $\mathrm{CH}_{3} \mathrm{CN}$ has been found to give blue emission at $453 \mathrm{~nm}$ upon addition of a protic solvent such as water. The model compound $\mathbf{5}$, which lacks a phenolic proton, however, does not exhibit the fluorescence turn-on under the same conditions. Spectral comparison between $\mathbf{4}$ and $\mathbf{5}$, in addition to dynamic light scattering (DLS) study, suggests that the fluorescence turn-on is associated with the excited state intramolecular proton transfer (ESIPT), rather than the AIE effect reported from the structural similar analogues $\mathbf{1}$.

Acquisition of the spectra of $\mathbf{4}$ at low temperatures reveals a dynamic fluorescence response of 4 to temperature: emission at $\sim 520 \mathrm{~nm}$ when the sample is frozen (below $-80{ }^{\circ} \mathrm{C}$ ), emission disappearance when warming to about $-70{ }^{\circ} \mathrm{C}$ (due to PET), and emission recurring at $475 \mathrm{~nm}$ after the frozen matrix is melting (above $-20^{\circ} \mathrm{C}$ ). The dynamic response points to that the AIE contribution may not be a major contribution here, since the emission of aggregate is not expected to be quenched by the reorganization of the surrounding water molecules. On the basis of the large Stokes' shift, the emission signals at $475 \mathrm{~nm}$ is assigned to ESIPT, whose turn-on can be attributed to the hydrogen bonding to the -NH- group that is responsible for PET. The assumption of the ESIPT emission at 475 $\mathrm{nm}$ is further supported by the dye's linear response to $\mathrm{Al}^{3+}$ ion. The opposite spectra shift upon $\mathrm{Al}^{3+}$ binding, i.e., red shift for $\mathrm{UV}$-vis absorption $\lambda_{\max }$ and blue shift for fluorescence $\lambda_{\mathrm{em}}$, further supports the assignment that the emission at $475 \mathrm{~nm}$ is arising from ESIPT. All the evidence thus consistently point to that the turn-on emission at $475 \mathrm{~nm}$ (upon addition of water at room temp) is due to the activation of ESIPT. The recognition of ESIPT emission in 
the hydrazine derivative materials will be a valuable guide for the future improvement in the related applications such as chemical sensor response. The results also suggest that the ESIPT turn-on could also contribute significantly to the fluorescence turn-on in a Schiff base material, which is different from the previously studied Schiff base $\mathbf{1}$ where AIE is considered to be the sole reason.

The fluorescence of $\mathbf{4}$ illustrates that the ESIPT turn-on can be an important factor in the fluorescence turn-on. The lack of AIE from the solution of $\mathbf{4}$ might be due to its low molecular mass and the presence of polar groups, whose good solubility minimizes aggregate formation in a dilute solution (e.g., $10^{-4} \mathrm{M}$ ). With a molecule of a relative stronger $\pi-\pi$ interaction, we anticipate that both AIE and ESIPT enhancement can be coupled together to give interesting material property, which awaits to be further explored.

\section{EXPERIMENTAL SECTION}

\section{General Consideration}

All reactions were carried out under aerobic conditions. All reagents were purchased through VWR, ethanol was purchased through Decon Laboratories, methanol was purchased through Sigma-Aldrich, and all materials were used as received without further purification with the exclusion of acetonitrile, which was collected using a PurSolv solvent purification system by Innovative Technologies. ${ }^{1} \mathrm{H}$ and ${ }^{13} \mathrm{C}$ data were collected using Varian 300, 500, and $750 \mathrm{MHz}$ instruments with all spectra referenced to deuterated solvents. Crystals of $\mathrm{C}_{9} \mathrm{H}_{10} \mathrm{~N}_{2} \mathrm{O}_{3}$ and $\mathrm{C}_{10} \mathrm{H}_{12} \mathrm{~N}_{2} \mathrm{O}_{3}$ were coated in paraffin oil and mounted on a CryoLoop and placed on the goniometer head under a stream of nitrogen cooled to $100 \mathrm{~K}$. The data were collected on a Bruker APEX II Duo CCD system equipped with a Mo ImuS microfocus source $(\lambda=0.71073 \AA)$. The unit cell was determined by using reflections from three different orientations. The data was integrated using SAINT.1 An empirical absorption correction and other corrections were applied to the data using SADABS. Structure solution, refinement, and modeling were accomplished by using the Bruker SHELXTL package. ${ }^{17}$

Structures were determined by full-matrix least-squares refinement of $F^{2}$ and the selection of the appropriate atoms from the generated difference map. Hydrogen atom positions were calculated and $\mathrm{U}_{\mathrm{iso}}(\mathrm{H})$ values were fixed according to a riding model. Data collection was on March 3, 2014 and April 7, 2014 for $\mathrm{C}_{9} \mathrm{H}_{10} \mathrm{~N}_{2} \mathrm{O}_{3}$ and $\mathrm{C}_{10} \mathrm{H}_{12} \mathrm{~N}_{2} \mathrm{O}_{3}$ respectivley. X-ray data were collected and solved by Pat Wagers of The University of Akron X-ray crystallography lab.

Synthesis of Schiff base (4)—N-(Methoxycarbonyl)hydrazine ( $0.150 \mathrm{~g}, 1.67 \mathrm{mmol})$ was dissolved into a minimal amount of ethanol, and 2-hydroxybenzaldehyde $(0.200 \mathrm{~g}, 1.64$ mmol) was added to the solution. The solution was refluxed overnight and allowed to cool. A white solid precipitated out and filtered off. It was recrystallized from ethanol and a white ( $0.276 \mathrm{~g}, 1.42 \mathrm{mmol}, 87 \%$ yield) powder was obtained. IR (mineral oil), $v\left(\mathrm{~cm}^{-1}\right): 3632.94$, 3541.32, 3201.09, 3164.29, 2943.49, 1040.29, 918.68, 762.13. ${ }^{1} \mathrm{H}$ NMR $(750 \mathrm{MHz}$, DMSO), $\delta: 11.284$ (s, N-H), $10.802(\mathrm{~s}, \mathrm{OH}), 8.217(\mathrm{~s},-\mathrm{CH}=\mathrm{N}-), 7.450$ (d, aromatic), 7.217 (dd, aromatic), 7.217 (d, aromatic), 6.854 (dd, aromatic), $3.676 \mathrm{ppm}\left(\mathrm{s},-\mathrm{CH}_{3}\right.$ ). Crystals suitable for single crystal X-ray diffraction were grown from a solution of ethanol. Crystal 
data for 4: $\mathrm{C}_{9} \mathrm{H}_{10} \mathrm{~N}_{2} \mathrm{O}_{3}, M=194.19$, orthorhombic, $a=5.0275(15) \AA, b=10.644(3) \AA$, $c=$ 17.143(5) $\AA, a=90^{\circ}, \beta=90^{\circ}, \gamma=90^{\circ}, V=917.4(4) \AA^{3}, T=100(2)$, space group $P 2(1) 2(1) 2(1), Z=4, \mu($ Mo K $a)=0.107 \mathrm{~mm}^{-1}, 4225$ reflections measured, and 1864 independent reflections $(R($ int $)=0.0399)$. The final R1 value was $0.0409(I>2 \sigma(I))$. The final $w R(F 2)$ value was $0.1005(I>2 \sigma(I))$. The final R1 value was 0.0486 (all data). The final wR(F2) value was 0.1067 (all data). The goodness of fit on F2 was 1.065.

\section{Synthesis of 2-Hydrazinecarboxylic Methoxyphenyl Methyl Ester (5) $-\mathrm{N}$ -}

(Methoxyxcarbonyl)hydrazine $(0.402 \mathrm{~g}, 4.46 \mathrm{mmol})$ was dissolved into the minimal amount of ethanol, and $o$-anisaldehyde $(0.5 \mathrm{~mL}, 0.544 \mathrm{~g}, 4 \mathrm{mmol})$ was added to the solution. The solution was refluxed and monitored via TLC until completion. The solution was concentrated down until solid started to precipitate out. The material was then recrystallized from ethanol, filtered and washed with cold ethanol to obtain a light gray powder $(0.324 \mathrm{~g}$, $39 \%$ yield) ${ }^{1} \mathrm{H}$ NMR (300 MHz, DMSO), $\delta: 11.025(\mathrm{~s}, \mathrm{~N}-\mathrm{H}), 8.362(\mathrm{~s},-\mathrm{CH}=\mathrm{N}-), 7.758$ (d, aromatic), 7.369 (dd, aromatic), 7.079 (dd, aromatic), 6.978 (d, aromatic), 3.827 (s, $-\mathrm{CH}_{3}$ ), $3.678\left(\mathrm{~s},-\mathrm{CH}_{3}\right) .{ }^{13} \mathrm{C}$ NMR (125 MHz, DMSO), $\delta: 157.8,154.1$ (Ar-HC=N), 140 (ester amide), 131.5, 125.7, 122.9, 121.1, 112.2, $56.1\left(\mathrm{Ar}-\mathrm{O}-\mathrm{CH}_{3}\right), 52.3$ (ester- $\left.\mathrm{CH}_{3}\right)$. Crystals suitable for single crystal $\mathrm{X}$-ray diffraction were grown from a solution of ethanol. Crystal data for 5: $\mathrm{C}_{10} \mathrm{H}_{12} \mathrm{~N}_{2} \mathrm{O}_{3}, M=208.22$, monoclinic, $a=17.013(3) \AA, b=7.2937(14) \AA$, c= 16.476(3) $\AA, \alpha=90^{\circ}, \beta=95.677(2)^{\circ}, \gamma=90^{\circ}, V=2034.4(7) \AA^{3}, T=100(2)$, space group $P 2(1) / c, Z=8, \mu(\mathrm{Mo} \mathrm{K} a)=0.102 \mathrm{~mm}^{-1}, 15707$ reflections measured, and 4126 independent reflections $(R($ int $)=0.0275)$. The final $\mathrm{R} 1$ value was $0.0381(I>2 \sigma(I))$. The final $w \mathrm{R}(\mathrm{F} 2)$ value was $0.0980(I>2 \sigma(I))$. The final R1 value was 0.0444 (all data). The final $w R(F 2)$ value was 0.1041 (all data). The goodness of fit on F2 was 1.032.

\section{Supplementary Material}

Refer to Web version on PubMed Central for supplementary material.

\section{ACKNOWLEDGMENTS}

This work was supported by NIH (Grant No. 1R15EB014546-01A1). We also thank the Coleman endowment from the University of Akron for partial support.

\section{REFERENCES}

1. Hong Y, Lam JWY, Tang BZ. Aggregation-Induced Emission. Chem. Soc. Rev. 2011; 40:53615388. [PubMed: 21799992]

2. Thomas SW, Joly GD, Swager TM. Chemical Sensors Based on Amplifying Fluorescent Conjugated Polymers. Chem. Rev. 2007; 107:1339-1386. [PubMed: 17385926]

3. Liu Z, He W, Guo Z. Metal Coordination in Photo-luminescent Sensing. Chem. Soc. Rev. 2013; 42:1568-1600. [PubMed: 23334283]

4. Carter KP, Young AM, Palmer AE. Fluorescent Sensors for Measuring Metal Ions in Living Systems. Chem. Rev. 2014; 114:4564-4601. [PubMed: 24588137]

5. Cotruvo JA Jr. Aron AT, Ramos-Torres KM, Chang CJ. Synthetic Fluorescent Probes for Studying Copper in Biological Systems. Chem. Soc. Rev. 2015; 44:4400-4414. [PubMed: 25692243]

6. Martínez-Mańẽz R, Sancenon F. Fluorogenic and Chromogenic Chemosensors and Reagents for Anions. Chem. Rev. 2003; 103:4419-4476. [PubMed: 14611267] 
7. Orosco RK, Tsien RY, Nguyen QT. Fluorescence Imaging in Surgery. IEEE Rev. Biomed Eng. 2013; 6:178-187. [PubMed: 23335674]

8. Wehry, EL. Effects of Molecular Structure on Fluorescence and Phosphorescence.. In: Guilbault, GG., editor. Practical Fluorescence. 2nd ed.. Marcel Dekker; New York: 1990. p. 75-126.

9. Tang W, Xiang Y, Tong A. Salicylaldehyde Azines as Fluorophores of Aggregation-Induced Emission Enhancement Characteristics. J. Org. Chem. 2009; 74:2163-2166. [PubMed: 19178143]

10. Gong WT, Zhang QL, Shang L, Gao B, Ning GL. A New Principle for Selective Sensing Cyanide Anions Based on 2-Hydroxy-Naphthaldeazine Compound. Sens. Actuators, B. 2013; 177:322326.

11. Formosinho SJ, Arnaut LG. Excited-State Proton Transfer Reactions II. Intramolecular Reactions. J. Photochem. Photobiol., A. 1993; 75:21-48.

12. Wang J, Pang Y. A Simple Sensitive ESIPT on-off Fluorescent Sensor for Selective Detection of $\mathrm{Al}^{3+}$ in Water. RSC Adv. 2014; 4:5845. [PubMed: 24839545]

13. Chu Q, Pang Y. Aggregation and Self-Assembly of Oligo(2,5-dialkoxy-1,4phenyleneethynylene)]s: An Improved Probe To Study Inter- and Intramolecular Interaction. Macromolecules. 2005; 38:517-520.

14. Sarkar S, Mandal S, Pramanik R, Ghatak C, Rao VG, Sarkar N. Photoinduced Electron Transfer in a Room Temperature Ionic Liquid 1-Butyl-3-methylimidazolium Octyl Sulfate Micelle: A Temperature Dependent Study. J. Phys. Chem. B. 2011; 115:6100-6110. [PubMed: 21526789]

15. Chu Q, Medvetz DA, Panzner MJ, Pang Y. A Fluorescent Bis(benzoxazole) Ligand: Toward Binuclear Zn(II)-Zn(II) Assembly. Dalton Trans. 2010; 39:5254-5259. [PubMed: 20440438]

16. Ingle, JD.; Crouch, SR. Spectrochemical Analysis. Prentice-Hall; Englewood Cliffs, NJ: 1988. p. 372-381.for a discussion of deviations from Beer's law

17. Sheldrick, GM. SHELX-97: Program for Crystal Structure Analysis. University of Gottingen; Gottingen, Germany: 1997. 
a: $A$

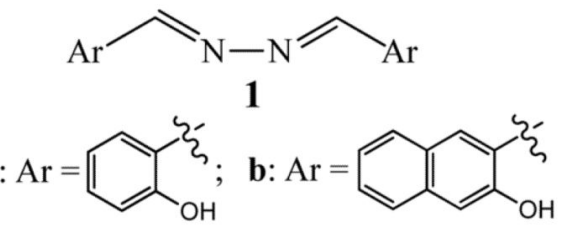<smiles>[R]Oc1ccccc1C=O</smiles>

3

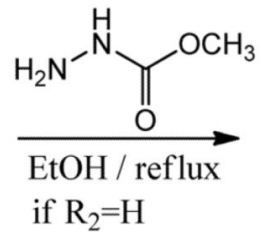

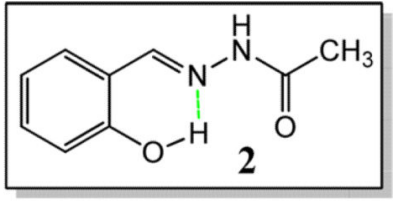<smiles>[R]Oc1ccccc1/C=N/NC(=O)OC</smiles>

$5\left(\mathrm{R}=-\mathrm{CH}_{3}\right)$

Scheme 1.

Chemical Structures of Schiff Bases 1 and 2, and Synthesis of (2'-

Hydroxybenzylidene)hydrazine Carboxylate (4) 

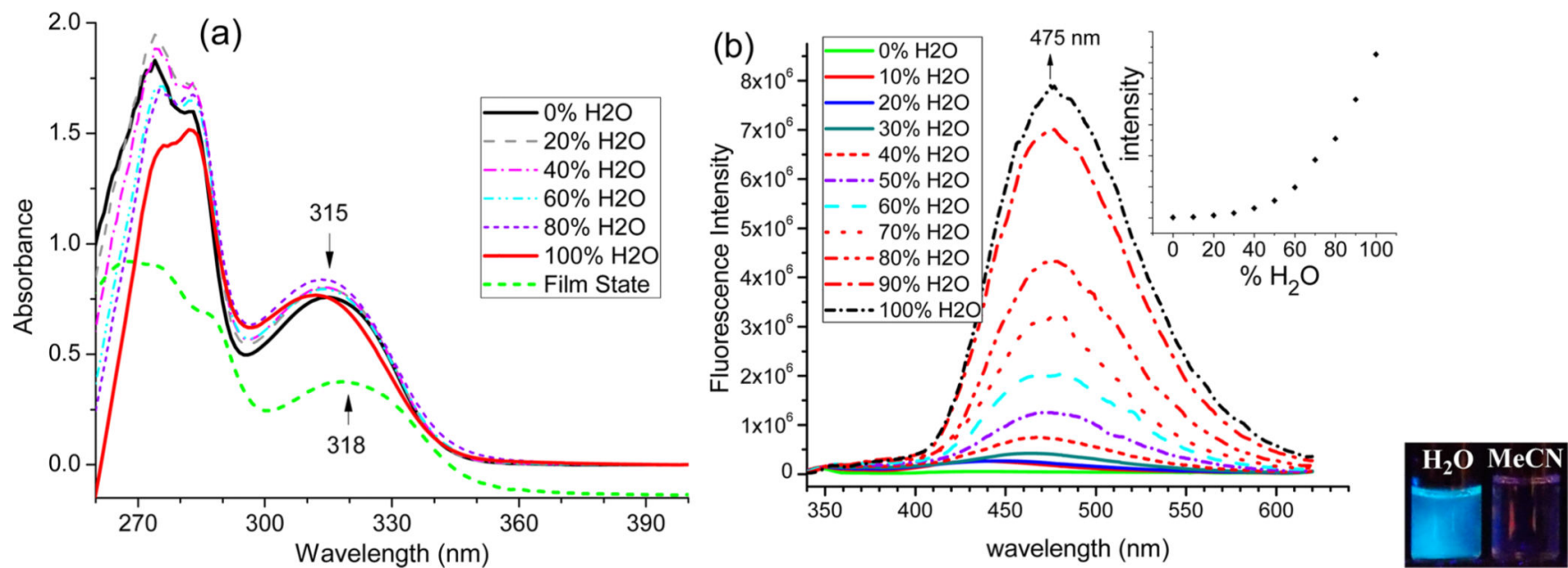

Figure 1.

(a) UV-vis absorption of $\mathbf{4}\left(10 \mu \mathrm{M}\right.$ concentration) in dry $\mathrm{CH}_{3} \mathrm{CN}$ or $\mathrm{CH}_{3} \mathrm{CN} / \mathrm{H}_{2} \mathrm{O}$ at $23{ }^{\circ} \mathrm{C}$.

The spectrum of film 4 (spin-cast on a quartz plate) is slightly offset for clarity. (b)

Fluorescence of 4 (10 $\mu \mathrm{M}$ concentration) in dry acetonitrile or $\mathrm{CH}_{3} \mathrm{CN} / \mathrm{H}_{2} \mathrm{O}$ in different ratios. The inset shows the relative signal intensity at $475 \mathrm{~nm}$ versus the water content. Excitation at $\sim 315 \mathrm{~nm}$. 


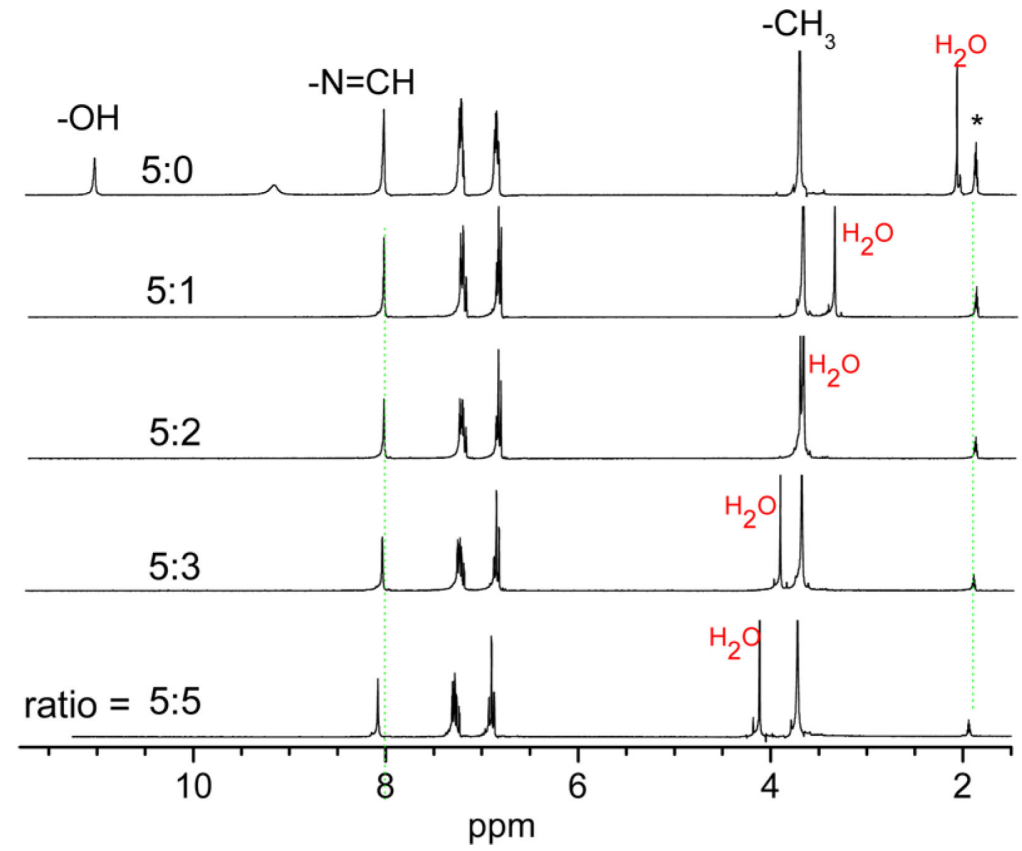

Figure 2.

${ }^{1} \mathrm{H}$ NMR of 4 in deuterated solvents, where the ratio of $\mathrm{CD}_{3} \mathrm{CN} / \mathrm{D}_{2} \mathrm{O}=5: 0,5: 1,5: 2,5: 3$, and 5:5. The starred signal at $1.9 \mathrm{ppm}$ is attributed to residual acetonitrile solvent. 


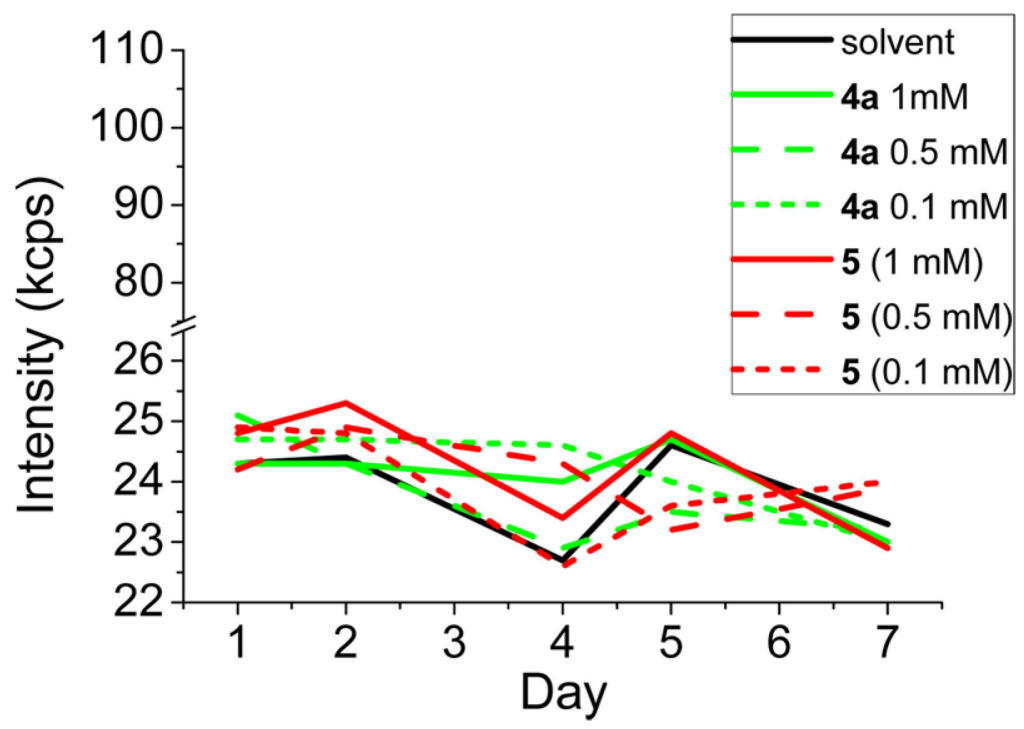

Figure 3.

Dynamic light scattering (DLS) data for $\mathbf{4}$ and $\mathbf{5}$ in solution. No observable aggregation was obtained over a 7 day period from a solvent system of $\mathrm{CH}_{3} \mathrm{CN}: \mathrm{H}_{2} \mathrm{O}(2: 3)$. 

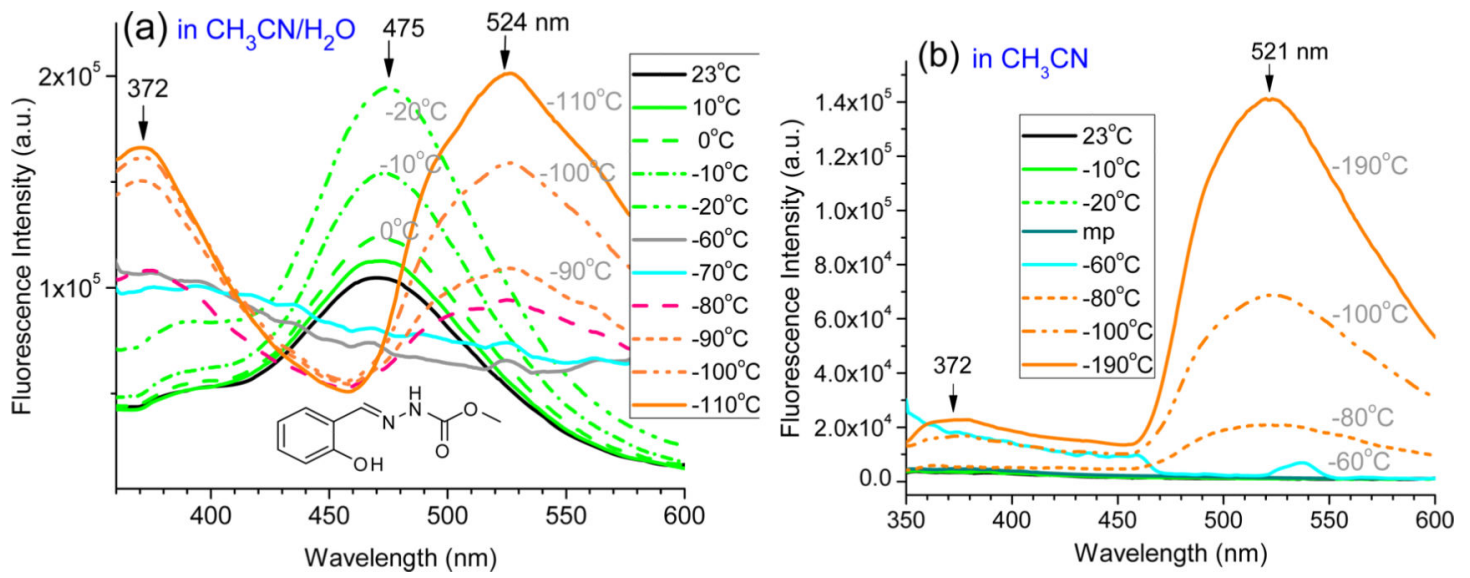

Figure 4.

Fluorescence of 4 (concentration $10 \mu \mathrm{M}$ ) in $\mathrm{CH}_{3} \mathrm{CN} / \mathrm{H}_{2} \mathrm{O}$ (volume ratio =3:1) (a) and in $\mathrm{MeCN}$ (b) at room and low temperature. Excitation at $320 \mathrm{~nm}$. 


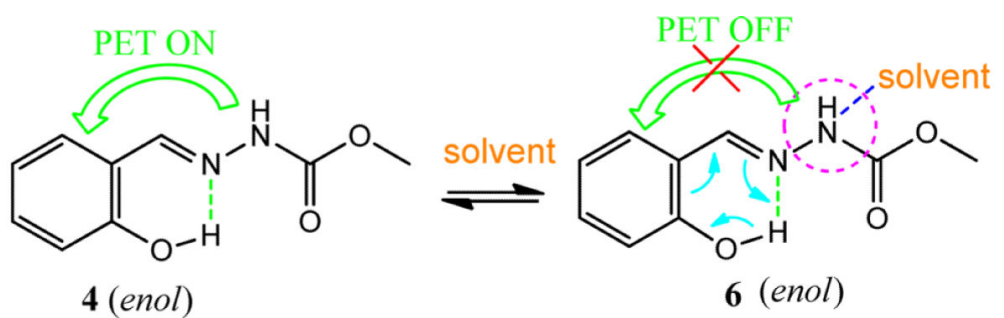

$$
\lambda_{\mathrm{em}}=358 \mathrm{~nm}
$$
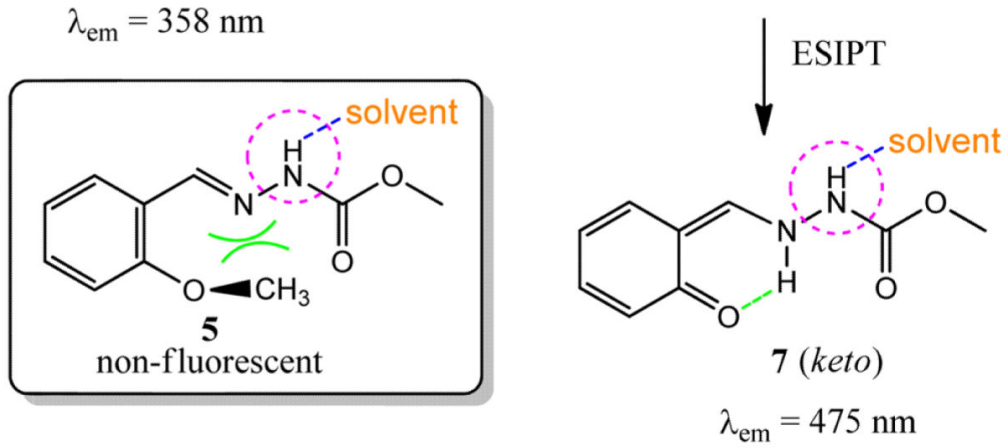

${ }^{a} \mathrm{~A}$ strong interaction of solvent molecules with amine removes the PET.

Scheme 2.

Proposed Mechanism for Fluorescent Turn-On, via ESIPT, in a Protic Solvent ${ }^{a}$ 


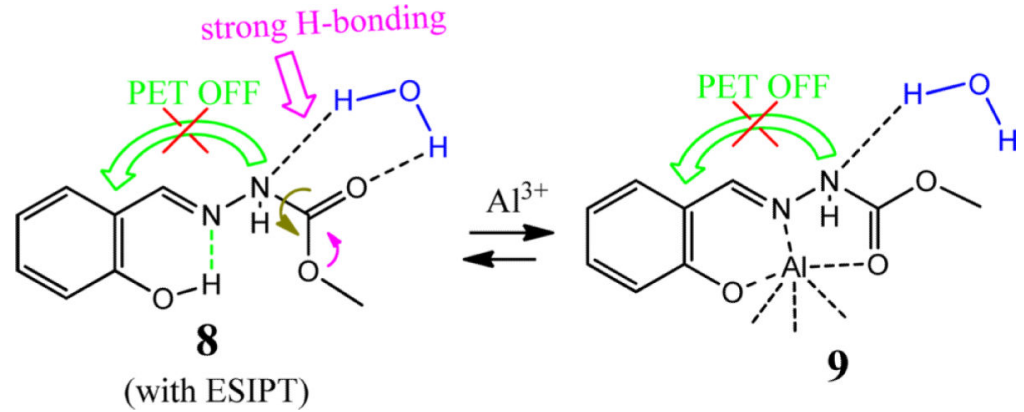

Scheme 3.

Solvated Molecule 8 Could Bind Zinc Cation, Which Removes the Hydrogen Atom To Disable the ESIPT 

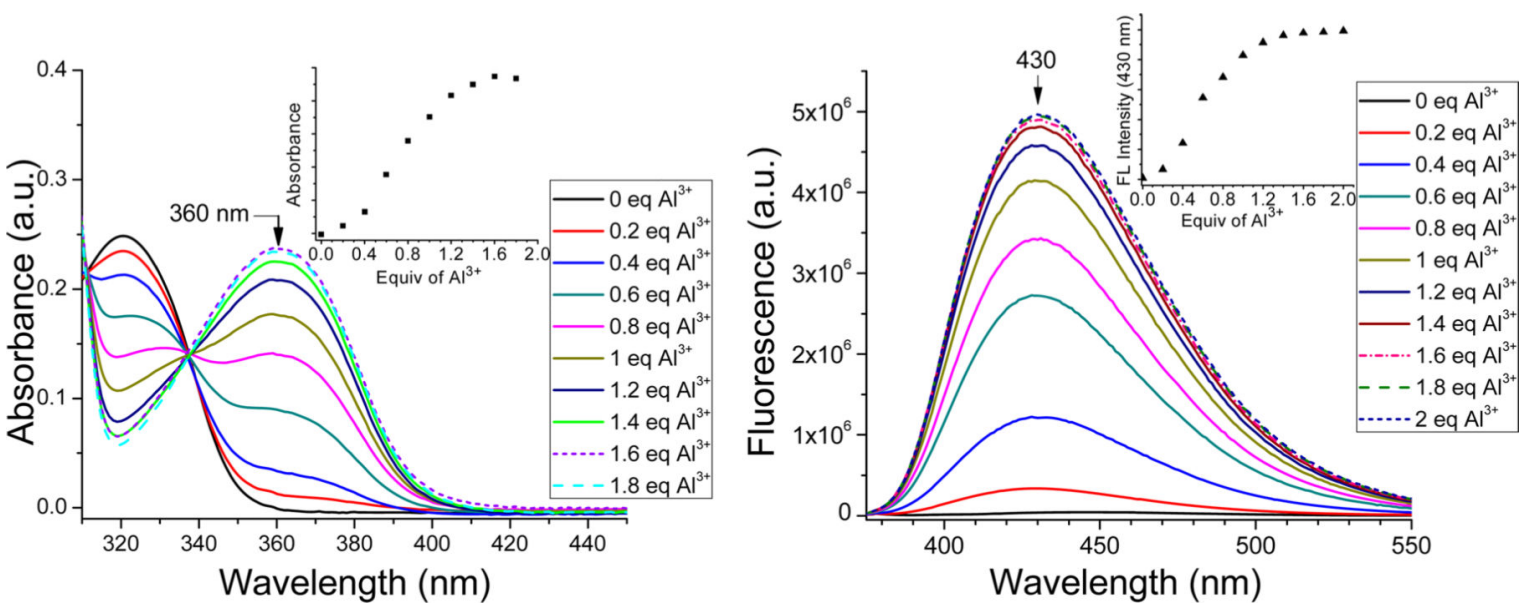

Figure 5.

UV-vis absorption (a) and fluorescence response (b) of $\mathbf{4}$ in methanol upon addition of different equivalent of $\mathrm{Al}\left(\mathrm{NO}_{3}\right)_{3}$. The inset plots the respective spectral response to $\mathrm{Al}^{3+}$ cation. 

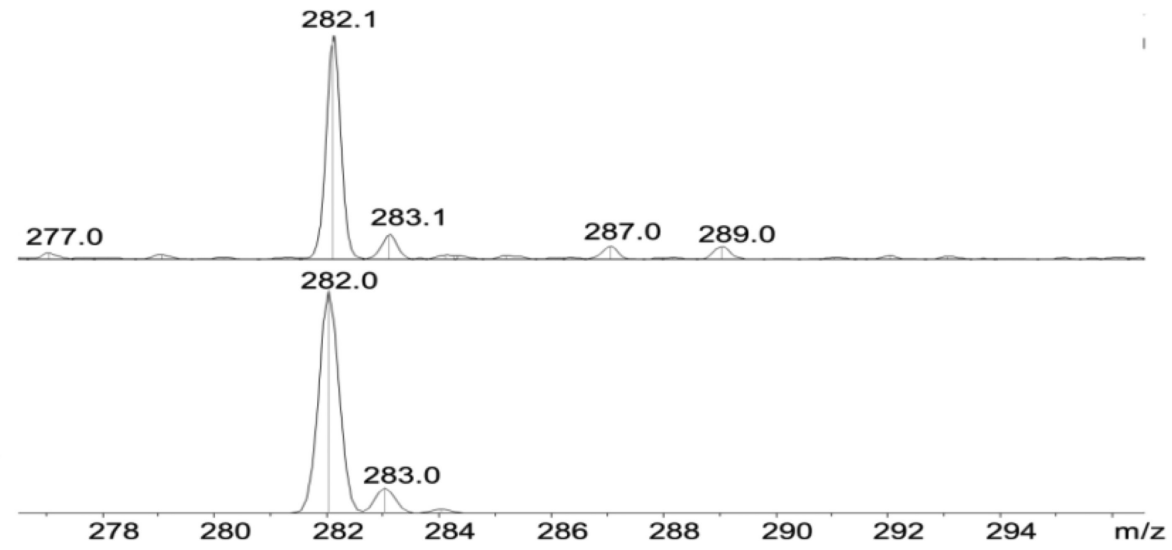

Figure 6.

Experimental (top) and calculated (bottom) isotope distribution for $\left[4+\mathrm{Al}^{3+}+\mathrm{NO}_{3}{ }^{-}\right]$. The mass spectrum was obtained in positive mode on a Bruker HCT Ion Trap mass spectrometer. All mass spectra were collected in methanol, after mixing 4 and $\mathrm{Al}(\mathrm{NO})_{3}$. 


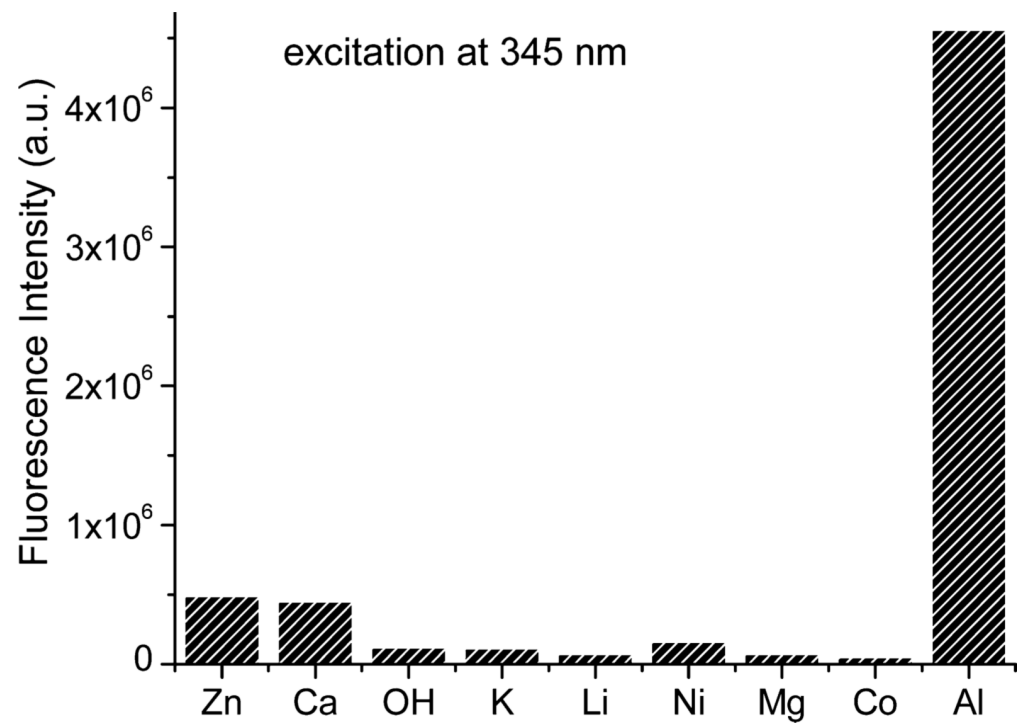

Figure 7.

Fluorescence response of 4 (concentration $10 \mu \mathrm{M}$ ) toward different metal ions, showing the selectivity for the $\mathrm{Al}^{3+}$ versus other metal ions and the hydroxide ion in metnanol. 


\section{Table 1}

Photophysical Properties of 4 and 5 in $\mathrm{MeCN}$ (before and after Addition of $\mathrm{Al}^{3+}$ Cation)

\begin{tabular}{ccccccc}
\hline compound & $\lambda_{\max }(\mathbf{n m})$ & emission $\lambda_{\text {em }}(\mathbf{n m})$ & $\phi_{\mathrm{L}}(\boldsymbol{\%})$ & $\lambda_{\max , \mathrm{L}+\mathrm{Al}}(\mathbf{n m})$ & $\left.\operatorname{emission}_{(\mathrm{L}+\mathrm{Al}} \mathbf{3}^{\mathbf{3}+}\right)$ & $\boldsymbol{\phi}_{\mathrm{L}+\mathrm{Al}}(\boldsymbol{\%})$ \\
$\mathbf{4}$ & 317 & 453 & 0.0368 & 358 & 447 & 22.6 \\
$\mathbf{5}$ & 314 & 355 & 0.028 & 314 & 359 & 0.031 \\
\hline
\end{tabular}

